\title{
Rol del sistema enzimático antioxidante bacteriano en la promoción del crecimiento de maní y maíz
}

Ludueña, Liliana $\mathrm{M}^{\left(1^{*}\right)}$., Taurian, Tania ${ }^{(1)}$,.

${ }^{1}$ Universidad Nacional de Rio Cuarto, Facultad de Ciencias Exactas, Físico-Químicas y Naturales, Departamento de Ciencias Naturales. Argentina. Agencia Postal 3.

*E-mail: lluduena@exa.unrc.edu.ar

Introducción: En la actualidad se les ha atribuido a las especies reactivas del oxígeno (EROs) un rol como moléculas señal en diversos procesos fisiológicos de la planta. Entre ellos, se encuentra la respuesta de defensa frente a diversos estreses abióticos y bióticos. Así, ante la presencia de un patógeno, parte del complejo sistema inmune de la planta es impulsado por una generación y acumulación de EROs que le permite mediar primero el reconocimiento del microorganismo, y luego el establecimiento de la respuesta de defensa. Aunque el anión superóxido $\left(\mathrm{O}_{2}^{-}\right)$es el primer producto generado, el peróxido de hidrógeno $\left(\mathrm{H}_{2} \mathrm{O}_{2}\right)$ es una especie más estable y por ello es más frecuentemente analizada en numerosos trabajos. Por otro lado, en las interacciones planta-microorganismos benéficos, se ha demostrado que el equilibrio oxidativo juega un papel importante. Así por ejemplo, diversos estudios han aportado pruebas convincentes de que la modulación de la producción de EROs juega un papel importante en los procesos de señalización durante el establecimiento de la simbiosis leguminosa-rizobio. En un trabajo previo del laboratorio, se comprobó un aumento en la producción de $\mathrm{H}_{2} \mathrm{O}_{2}$ en raíces de plantas de maní cuando eran inoculadas con la bacteria solubilizadora de fosfato Serratia sp. S119 a tiempos cortos post contacto de ambos organismos. De esta manera, es posible especular que el éxito de dicha interacción benéfica se vincule con la participación del sistema antioxidante bacteriano en la atenuación de dicho estallido oxidativo. Con el objetivo de determinar el requerimiento del sistema antioxidante de Serratia sp. S119 para el establecimiento de su interacción con la planta y ejercer el efecto benéfico sobre la misma, se inhibió la actividad de enzimas peroxidasas bacterianas y se realizaron ensayos de inoculación en plantas de maní y maíz.

Materiales y métodos: Se realizaron ensayos de inoculación en plantas de maní y maíz con la cepa Serratia sp. S119 cuyas enzimas peroxidasas estaban inhibidas con el reactivo ácido Salicilhidroxamico (SHAM). Inicialmente se evaluó la concentración de SHAM a ser utilizada en los ensayos propuestos mediante la determinación de la viabilidad de Serratia sp. S1 19 creciendo en presencia de diferentes dosis de este compuesto $(0,2,0,5,1$ o $2 \mathrm{mM})$ en medio LB. A continuación se determinó la actividad peroxidasas totales (PX) en cultivos de Serratia sp. S119 adicionado con SHAM siguiendo la metodología descripta por Sosa Alderete y col. (2009). Posteriormente, Serratia sp. S119, creciendo en presencia y en ausencia de SHAM, fue inoculada en plántulas de maní y maíz. Para el crecimiento de las plantas se empleó como soporte arena y vermiculita (1:2) estéril y se las mantuvo en condiciones controladas siguiendo la metodología puesta a punto en el laboratorio. Las plantas fueron regadas regularmente con medio Hoagland (Hoagland y Arnon, 1950) estéril sin P y cosechadas a los 40 y 21 días postinoculación para maní y maíz, respectivamente. Se analizó en las mismas la biomasa aérea y radical, longitud aérea y radical y el contenido de $\mathrm{P}$ en parte aérea. El ensayo consistió en tres réplicas biológicas con un $\mathrm{n}=10$. Los datos experimentales fueron analizados empleando el análisis de la varianza y la prueba de LSD o Tukey para comparaciones múltiples $(\mathrm{p}<0,05)$.

Resultados: Los resultados obtenidos indicaron que la adición de SHAM $0,2 \mathrm{mM}$ no afectó el crecimiento y viabilidad de Serratia sp. S119 en ninguno de los tiempos analizados y redujo en un $80 \%$ la actividad peroxidasa (PX) en fase exponencial de crecimiento (6 hs). La inoculación de maní y maíz con Serratia sp. S119, que presentaba inhibida la actividad peroxidasa, indicó que los parámetros de crecimiento vegetal eran similares a las plantas inoculadas con la cepa que creció en ausencia de SHAM.

Conclusiones: La actividad de las enzimas peroxidasas de Serratia sp S119 no cumpliría un rol esencial durante la interacción de esta bacteria con plantas de maní y maíz en el sistema de estudio utilizado. 